\title{
Coaching para el empoderamiento de mujeres con discapacidad
}

\section{Coaching for empowerment of women with disabilities}

\section{Palabras clave}

Empoderamiento, coaching, mujeres, discapacidad, proceso, aprendizaje, protagonista.

\section{Keywords}

Empowerment, coaching, women, disability, process, learning, protagonist.

\section{Aurora Tirado}

<auroralunahuelva@gmail.com>

Asociación Onubense de Mujeres Con Discapacidad LUNA. España

\section{Introducción}

En los debates sobre Ciencias Sociales, el empoderamiento ocupa un lugar cada vez más central. Este término nace en Estados Unidos en la década de los sesenta durante los movimientos de derechos civiles, respondiendo a la necesidad de generar cambios con respecto a las relaciones de poder entre géneros (Charlier et al., 2007).

Charlier et al. (2007) se fijan en el empoderamiento como un doble proceso de adquisición de poder. Por un lado, individual, es decir, la adquisición de una mayor autonomía, de la capacidad de autodeterminación, de medios que permitan a todas gozar de una mayor elección de vida. Y, por otro lado, colectivo, es decir, la capacidad que un grupo puede desarrollar para influir en los cambios sociales con el fin de alcanzar una sociedad justa e igualitaria, especialmente en relaciones entre hombres y mujeres.

Por su parte, Schuler (1997) define el empoderamiento como "proceso por medio del cual las mujeres incrementan su capacidad de configurar sus propias vidas y su entorno, una evolución en la concientización de las mujeres sobre sí mismas y su estatus y en su eficiencia en las relaciones sociales".

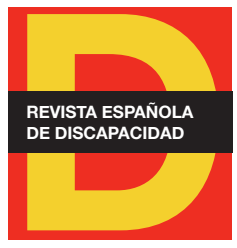

Para citar:

Tirado, A. (2018): "Coaching para el empoderamiento de mujeres con discapacidad". Revista Española de Discapacidad, 6 (I): 291-304.

Doi: <https://doi.org/10.5569/23405104.06.01.15> 
Esta misma autora también hace énfasis en los procesos cognitivos, psicológicos y económicos que subyacen al empoderamiento. Es decir, ve también necesario reconocer los obstáculos mentales y económicos que dificultan el cambio, por lo que enfatiza la importancia de la reflexión crítica para lograr una acción transformadora (Hernández y García, 2008). Las manifestaciones necesarias para el proceso de empoderamiento, según esta misma autora, son:

1. Sentido de seguridad y visión del futuro.

2. Capacidad de ganarse la vida.

3. Capacidad de actuar eficazmente en la esfera pública.

4. Mayor poder de tomar decisiones en el hogar.

5. Participación en grupos no familiares y uso de grupos de solidaridad como recursos de información y apoyo.

6. Movilidad y visibilidad en la comunidad.

La finalidad de este artículo es dar a conocer la iniciativa llevada a cabo en la Asociación LUNA de Mujeres con Discapacidad sobre empoderamiento en clave de género a través del coaching. Para ello, se realizó una revisión bibliográfica en busca de otros casos en los que el coaching se hubiera utilizado como herramienta para el fomento del empoderamiento de las mujeres, siendo casi nula la bibliografía al respecto como herramienta para su trabajo grupal. Sí se encontró un uso a nivel individual por coaches particulares y referencias sobre la utilidad del coaching para el empoderamiento de las personas. Como lo define Pittini (2017): "El Coaching es una herramienta poderosa que empodera a las personas, a los equipos, a las organizaciones y nos transforma en lo que queremos ser".

A pesar de que el coaching es un concepto que podría parecer relativamente "nuevo", hay autores que ven en la mayéutica de Sócrates sus inicios, como el arte de hacer preguntas. Lo cierto es que, como afirma Sans (2012), los orígenes del coaching no son precisos, definidos, asignables a un autor o a una corriente de pensamiento, si no que confluyen en él numerosas ciencias, disciplinas y pensadores.

Autores como Ravier (2005) o Sans (2012) sitúan el origen de la palabra coach de la palabra húngara "kocsi" que significa carreta especial. El coaching transporta a las personas de un lugar a otro, es decir, del lugar donde están al lugar donde quieren estar (Sans, 2012).

Hay autores que definen el coaching de manera literal de su traducción del inglés como un "entrenamiento" (Sans, 2012), otros lo ven como un arte (Wolk, 2003 o Galway en Sans, 2012), una disciplina, un procedimiento, una técnica, una herramienta e incluso como un estilo de vida. Nos decantamos más por estas dos últimas, el coaching como un proceso de aprendizaje que nos permite conocer herramientas-bien nuevas, bien olvidadas- en nuestro interior, que nos permitan llegar a la situación ideal que queremos conseguir partiendo desde nuestro momento real y actual (en la línea de Rafael Echevarría o John Whitmore).

En nuestras sesiones solemos romper el hielo preguntándoles a las mujeres: pero bueno, ¿qué es esa "palabrota"?, ¿qué significa coaching? Pues bien, viene a decir que si siempre vamos por el mismo camino llegaremos al mismo destino. Si queremos llegar a un destino diferente tendremos que hacer cosas dife- 
rentes, y es en ese espacio donde el coaching nos aporta las herramientas necesarias para conseguirlo. Nuestro objetivo con la puesta en marcha de estos talleres tomó ese enfoque. Queríamos que las mujeres que participaran en nuestros talleres pasaran de un lugar con un bajo autoconcepto, pocas habilidades sociales y capacidad de tomar decisiones hacia un lugar de empoderamiento que les permitiera mejorar su autoconcepto, mejorar sus habilidades sociales a la hora de decir que no o hacer peticiones, así como en la toma de decisiones, aspectos todos ellos que, como ya vimos anteriormente, según Hernández y García (2008) son necesarios para el proceso de empoderamiento.

Aunque coaching no es sólo eso, es mucho más, ya que nos permite también una mirada crítica y un espacio de autorreflexión y autocrítica que permita cambiar de gafas con las que mirar el mundo, cambiar de la negatividad a la positividad, una transformación personal, pues al ampliar nuestra visión del mundo se abren nuevas oportunidades y posibilidades en él, un crecimiento personal y la posibilidad de adoptar el papel de protagonistas de nuestra vida.

Leonardo Wolk define a un coach como un soplador de brasas, habla de despertar para recordar. Ve al coach como un facilitador del aprendizaje que acompaña al otro en una búsqueda de su capacidad de aprender para generar nuevas respuestas.

Para John Whitmore el coaching consiste en liberar el potencial de una persona para incrementar al máximo su desempeño. Consiste en ayudarle a aprender en lugar de enseñarle.

Al contrario que otros programas y talleres de empoderamiento en los que la persona facilitadora poseía todo el conocimiento e importancia, en nuestros talleres el coach o persona facilitadora deja de ser la persona protagonista y cede ese protagonismo, en nuestro caso, a las mujeres con discapacidad que han disfrutado de unos talleres basados en este tipo de metodología. Y es que la propia práctica del coaching nos aporta una manifestación del proceso de empoderamiento que requiere acción. Al igual que sucede con los procesos de empoderamiento, el coaching trabaja desde una doble vertiente que se ha puesto en práctica en nuestros talleres ya que, aunque también llevamos a cabo sesiones y procesos individuales desde nuestra asociación, toman especial relevancia los talleres grupales. Y es que "en el coaching grupal, más allá de un aprendizaje personal se genera, además, cohesión entre los integrantes del grupo y aprendizaje interpersonal" (Wolk, 2007: 26). Además, los temas a tratar, a pesar de ser personales, le servirán no sólo a la persona que los cuenta si no a las otras mujeres por identificación. Aquí entra en juego otro factor que aprendemos en coaching, bien como herramienta o como cambio de mirada: la liviandad, que es la emoción a través de la cual miramos los acontecimientos de la vida restándoles peso o trascendencia. En la liviandad somos capaces de reírnos de nosotras mismas en situaciones problemáticas o de dificultad ${ }^{1}$. Y esto aparece especialmente en las sesiones grupales, ya que por un lado nos damos cuenta de que nuestra historia no es única si no que hay a más personas a las que les ocurre lo mismo que a nosotras, e incluso de que hay personas con grandes historias de lucha y aprendizaje que nos aportan esa liviandad a nuestra propia realidad.

Nos quedamos con la frase de Goethe, "lo mejor que puedes hacer por los demás no es enseñarles tus riquezas si no hacerles ver las suyas propias" (citado en Wolk, 2003: 23). Y es que el coach no le dice a la otra persona qué es lo que tiene que hacer, ni qué decir ni cómo ser. Entre las coachees (referido a las mujeres

1. Ver: http://ciempre.wikidot.com/liviandad. 
que han recibido las sesiones de coaching) y la coach se crea un vínculo y una relación íntima y confidencial, así como con el resto de compañeras, creándose un espacio libre de juicios.

Siguiendo a Wolk (2003), el coaching es un proceso bien definido, con inicio y fin, estableciendo metas claras y diseñando acciones para alcanzar los resultados deseados.

Como lo define León (1996: 9), empoderarse significa que las personas adquieran el control de sus vidas, logren la habilidad de hacer cosas y de definir sus propias agendas. Es en este sentido en que apostamos por el uso del coaching como herramienta para lograr el empoderamiento de las mujeres con discapacidad de la asociación LUNA, así como, en palabras de Cook, para responder al deseo de contribuir a que las transformaciones de las relaciones de poder (entendidas en su sentido más amplio) entre hombres y mujeres vayan acompañadas de transformaciones en el lenguaje que reflejen nuevas construcciones e imaginarios sociales (Cook, 1996: 7).

\section{Metodología}

El objetivo del presente trabajo es fomentar el empoderamiento de las mujeres con discapacidad a través del coaching. Para ello, necesitábamos conocer de primera mano cómo es la realidad de las mujeres con discapacidad. Y la realidad es, como se ha podido observar desde la asociación LUNA tanto en los talleres grupales como en las atenciones individualizadas, que sufren una múltiple discriminación², la primera por ser mujer, la segunda por su condición de discapacidad y la tercera porque, en la gran mayoría, tienen una baja autoestima y percepción de sí mismas, tanto física como sexualmente, debido al estigma social y a la imagen social que recae sobre ellas. En ocasiones se suman otras asociadas a su procedencia social, étnica o población de origen...

Es por ello que vimos la necesidad y la oportunidad de llevar a cabo en nuestra Asociación Onubense de Mujeres con Discapacidad, LUNA, la realización de talleres de coaching en clave de género, siendo éste el universo de nuestra muestra.

El objetivo de nuestros talleres de coaching ha sido "sacar el máximo potencial de las usuarias o coachees, buscando que éstas encuentren los recursos que tienen dentro y se empoderen ellas mismas a través de una actitud mental positiva, de un aumento de su autoestima y de la creación de nuevas redes de apoyo entre ellas".

Fue en una fase posterior cuando nos planteamos la evaluación de la aplicación del programa de empoderamiento a través del coaching en mujeres con discapacidad.

2. Como se muestra en el estudio editado por el Observatorio estatal de la Discapacidad "Personas con discapacidad y discriminación múltiple en España: situación y propuestas" (Jiménez, 2017), donde se analizan los diferentes factores que influyen para que las personas con discapacidad sufran situaciones de discriminación múltiple, como son el género, la edad, el hábitat, el origen étnico que junto a la discapacidad multiplican la vulnerabilidad y la restricción de opciones de las personas con discapacidad. 


\section{- Instrumentos}

Al igual que sucede en las habilidades sociales (ya que es necesaria su adquisición y puesta en práctica en diferentes ámbitos concretos que mencionamos anteriormente para hablar de empoderamiento), los tres métodos más comunes para su evaluación son las observaciones conductuales, el role-playing y las escalas (Bielecki y Swender, 2004), siendo estos tres métodos los utilizados para este trabajo. En cada sesión de coaching se hacía un registro conductual de las dinámicas realizadas para poder estudiar la evolución de cada una de las mujeres. El role-playing se ha utilizado tanto como herramienta de entrenamiento de habilidades sociales como para decir no, realizar peticiones, hacer reclamaciones, así como a modo de evaluación para ver el progreso en este sentido.

La escala utilizada en este trabajo de aproximación ha sido una Escala Likert compuesta por diferentes ítems que se entregaron en un cuestionario inicial el primer día del taller y, de nuevo, en una evaluación final el último día. Y es que como refleja Guil (2006), las escalas sumativas son debidas a Likert (1932), que fue el primero en introducirlas para medir actitudes, tomándolas de técnicas de medida de la personalidad (Morales Vallejo, 2000: 46). En este método se supone que todos los ítems miden con la misma intensidad la actitud que se desea medir y es el encuestado el que le da una puntuación, normalmente de uno a cinco, en función de su posición frente a la afirmación sugerida por el ítem. La actitud final que se asigna al encuestado será la media de la puntuación que éste da a cada uno de los ítems del cuestionario.

Para la construcción de los ítems nos basamos en las manifestaciones necesarias que según Schuler (1997) se han de dar en el proceso de empoderamiento: 1 . sentido de seguridad y visión del futuro, 2. capacidad de ganarse la vida, 3. capacidad de actuar eficazmente en la esfera pública, 4. mayor poder de tomar decisiones en el hogar, y 5. participación en grupos no familiares y uso de grupos de solidaridad como recursos de información y apoyo.

Para ello, se ha tomado de referencia el Instrumento para Medir el Empoderamiento de la Mujer (IMEM), que se creó como indicador que nos permitiera determinar en qué medida y con qué características se daba el proceso de empoderamiento (Hernández y García, 2008).

Y, por otro lado, incluimos en el cuestionario final ítems Likert sobre la satisfacción de los talleres, los materiales, la persona facilitadora, el espacio y el horario.

Ambos se medían de 1 a 5 siendo 1 la puntuación más baja y 5 la máxima puntuación sobre satisfacción. En el caso del cuestionario relacionado con el empoderamiento, 1 correspondía con total desacuerdo, 2 desacuerdo, 3 ni acuerdo ni desacuerdo, 4 de acuerdo y 5 total acuerdo.

Han sido varias las limitaciones encontradas en relación con la metodología. Por un lado, la muestra (teniendo algunas bajas al inicio de cada taller por lo que hasta ese momento no se pudo cerrar, incorporándose en dos grupos cuatro mujeres), la falta de tiempo para el diseño de la evaluación ya que dicho taller se encuadraba en el marco de una subvención por lo que debíamos estar sujetos a dichos plazos con fecha límite de inicio y fin de los talleres, el número de sesiones (se vio la necesidad de ser más amplio, ya que pudimos constatar la necesidad de las participantes de expresarse y trabajar los contenidos propuestos para lo que sería adecuado sesiones de mayor duración, tal como reflejaron las mujeres en sus evaluaciones finales). 
Por último, la decisión sobre la utilización del Instrumento para Medir el Empoderamiento de la Mujer (IMEM) fue tomada durante la fase de diseño de la evaluación, pocos días antes de la ejecución del cuestionario inicial, por lo que se optó sólo por una aproximación, adaptando ítems de dicho indicador en lugar de su uso al completo.

Para futuras investigaciones sería deseable profundizar en la esfera de la capacidad de ganarse la vida. Para ello, sería oportuno que en un nuevo programa se incluyera coaching para el empleo aumentando en ocho el número de sesiones, y que para su evaluación se emplee el IMEM en su totalidad, así como el registro conductual y el role-playing -en este caso, el cuestionario de evaluación sólo estaba compuesto por 13 ítems frente a los 34 que configuran el IMEM ya que, como recomienda Morales Vallejo (2000: 68), el número definitivo del cuestionario debe oscilar entre 20 y 25 ítems (Guil, 2006)-.

\section{- Población y muestra}

Este programa de empoderamiento a través de coaching se dirigió a las mujeres con discapacidad de la Asociación Onubense de Mujeres con Discapacidad LUNA, siendo 83 las beneficiarias de dicho programa de las 534 socias de la asociación y, por lo tanto, la muestra objeto de estudio. Un dato importante a destacar es que en este periodo se aumentó el número de socias a 624, siendo los talleres de coaching de los más demandados. Se realizaron seis grupos: el primer grupo contó con 12 usuarias y el resto de grupos tuvieron la siguiente composición: dos grupos de 13 personas y tres grupos de 15 personas.

Todos los datos se obtuvieron de estos grupos participantes en el programa de coaching. No se ha utilizado ningún grupo de control con mujeres con discapacidad de la asociación que no participaran en estos talleres ya que, si bien hubiera resultado de gran riqueza metodológica, no fue contemplado en el diseño del mismo, lo que sí se tendrá en cuenta en futuras investigaciones.

El contenido del taller se distribuyó en seis sesiones, a continuación se muestra cuadro resumen de las sesiones:

Cuadro 1. Resumen de las sesiones del programa de coaching
\begin{tabular}{|l|l|l|l|}
\hline Sesiones & Objetivos & Actividades & Metodología \\
\hline 1 & $\begin{array}{l}\text { Aplicar el Cuestionario } \\
\text { Inicial. }\end{array}$ & $\begin{array}{l}\text { Sesión de evaluación del } \\
\text { empoderamiento previo a los } \\
\text { talleres. }\end{array}$ & $\begin{array}{l}\text { Explicación del cuestionario inicial. } \\
\text { Dinámica de presentación. } \\
\text { Entrega del cuaderno de ejercicios. }\end{array}$ \\
\hline 2 & $\begin{array}{l}\text { Crear una generación de } \\
\text { contexto. }\end{array}$ & $\begin{array}{l}\text { Enemigos del aprendizaje. } \\
\text { Video-fórum. }\end{array}$ & $\begin{array}{l}\text { Introducción mediante PowerPoint de qué es } \\
\text { coaching y empoderamiento. } \\
\text { Dinámicas en pareja y grupales. }\end{array}$ \\
\hline 3 & Explorar su situación actual. & $\begin{array}{l}\text { Rueda de la vida DAFO. } \\
\text { QT/QNT/NQNT/NQT. }\end{array}$ & $\begin{array}{l}\text { Realización de ejercicios individuales. } \\
\text { Dinámicas en pareja. } \\
\text { Resultados en plenario. }\end{array}$ \\
\hline 5 & $\begin{array}{l}\text { Buscar y visualizar su } \\
\text { situación ideal. }\end{array}$ & Dinámica de visualización. & $\begin{array}{l}\text { Trabajo individual mediante recortes y cartulina. } \\
\text { Trabajo en parejas para trabajar. preguntas } \\
\text { enfocadas al futuro. }\end{array}$ \\
\hline 6 & $\begin{array}{l}\text { Conocer y practicar la } \\
\text { comunicación eficaz. }\end{array}$ & $\begin{array}{l}\text { Role-playing. } \\
\text { "Decir no". } \\
\text { Hacer peticiones eficaces. }\end{array}$ & $\begin{array}{l}\text { Role-playing. } \\
\text { Dinámicas. }\end{array}$ \\
\hline Aplicar evaluación final. & Cuestionario evaluación final & $\begin{array}{l}\text { Realización de la evaluación final y sugerencias. } \\
\text { Feedback y despedida. }\end{array}$ \\
\hline
\end{tabular}

Fuente: elaboración propia. 


\section{- Datos sociodemográficos}

La edad media de las usuarias es de 58 años de edad. La situación laboral predominante es, con cerca de un $70 \%$, mujeres que se encuentran en situación de desempleo, seguido de un $20 \%$, aproximadamente, de aquellas que están jubiladas o con pensión de viudedad o baja médica y, de manera minoritaria, aquellas que se encuentran trabajando de manera activa con un $10 \%$.

El nivel de estudios de las usuarias es diverso predominando aquellas que poseen el Graduado Escolar con un $43 \%$, seguido de usuarias sin estudios al igual que aquellas que tienen Formación Profesionalb con un 20 \% cada categoría. En menor proporción nos encontramos con usuarias en posesión de título de Bachiller con un $10 \%$ y un $7 \%$ aquellas con estudios universitarios.

\section{- Procedimiento}

Nuestro propio desarrollo de los talleres ha sido un proceso de aprendizaje y ha necesitado una evolución, desde la gestación de este proyecto pasando por su difusión, puesta en marcha y reproducción de nuevas ediciones gracias a su acogida favorable y al boca a boca. El objetivo de este artículo es describir algunos aspectos de este proceso que puedan servir de utilidad a otras iniciativas similares.

Uno de los puntos a destacar es que creemos en lo que hacemos y creemos en el potencial que tienen nuestras mujeres. Creemos en la efectividad del coaching ya que la propia facilitadora de coaching había experimentado un proceso personal y profesional que le ha aportado un crecimiento, una visión más amplia y diferentes puntos de vistas que se dan en una misma realidad. $Y$ es que existe una gran diferencia entre lo que es el mundo y nuestra percepción de él.

Cuando comenzamos los talleres, nuestra primera sesión estuvo compuesta por seis mujeres, en el siguiente llegamos a tener más de treinta, por lo que tuvimos que realizar grupos cerrados y reducidos para su mayor aprovechamiento del tiempo y espacio. Y es que así son los procesos y los aprendizajes. Como decía Albert Einstein (citado en Wolk, 2003:35), "aprendizaje es experiencia, todo lo demás es información".

Hablamos de sentimientos, de emociones y es que éste es otro punto importante de nuestro taller. Durante el proceso, y de manera específica, practicamos para identificar y reconocer nuestras emociones, gestionarlas e incluso permitirnos experimentarlas. Todo necesario, todo en su justa medida para desarrollar una vida plena y equilibrada.

Otra particularidad de los talleres realizados es la manera en la que se desarrollan las sesiones, ya que como hemos señalado anteriormente, aquí lo importante es "aprender a aprender", siendo la metodología de las sesiones dinámica, de manera vivencial, mediante la propia experiencia, incorporando nuevos hábitos a nuestra mochila de habilidades y comportamientos mediante el entrenamiento de habilidades sociales y de la realización de ejercicios de role-playing. La programación de los talleres se basó en trabajar las manifestaciones, ya citadas anteriormente por Schuler, que se deben dar en un programa de empoderamiento siguiendo los pasos que deben darse en un proceso de coaching. La programación fue la siguiente:

Los datos sociodemográficos mostrados en el apartado de la población muestral y extraídos del cuestionario inicial (presentando una puntuación media de 2,6 sobre 5), nos permitieron entender la baja autoestima 
que nuestras usuarias presentaban al iniciar los talleres (también incluido un ítem al respecto). Aunque es cierto que tanto la formación como la situación laboral son aspectos que pueden condicionar la autoestima de una persona, igual de cierto es que encontramos personas con baja autoestima sea cual sea su situación laboral y formación. $Y$ aunque existen muchas definiciones sobre autoestima, siguiendo investigaciones como las de Ortega et al. (2001: 48): "Lo que aparece claro en todas las definiciones de la autoestima es su origen social. Nadie nace con alta o baja autoestima. Ésta se aprende en la interacción social con las personas más significativas: padres, amigos, profesores y el entorno familiar, sobre todo, durante la infancia y la adolescencia, aunque no podamos hablar con rigor de un proceso que ha llegado a su término, sino que permanece siempre abierto mientras estemos en contacto con los demás, y nuestras conductas puedan ser valoradas como positivas o negativas."

En nuestra experiencia, tras cada grupo hemos comprobado que el coaching favorece la creación de espacios nuevos y libres de juicios, lo cual ha permitido contextos nuevos y diferentes donde las mujeres han podido ser ellas mismas. Libres de participar o pasar en cada momento, de expresar o callar, de reír o llorar, cerrar los ojos, estar descalzas, abrir el corazón o cerrarse en banda, bailar, besar o abrazar. Y, lo más importante, cambiar su propio autoconcepto.

Hemos podido contemplar ese proceso de aprendizaje que han llevado a cabo las mujeres, siendo además parte del contenido del taller el trabajar los miedos, ya que ese aprendizaje, siguiendo a Wolk (2007: 35), "requiere la voluntad y la acción de movernos de una zona que arbitrariamente llamaremos de confort, a otra zona que llamaremos de expansión". Es en esta última donde se produce principalmente el aprendizaje. Y esto lo hemos venido trabajando en las sesiones. La zona de confort no siempre es confortable pero sí predecible. Solemos preferir lo malo conocido que lo bueno por conocer. Por ello, hemos trabajado este ámbito, para ver el aprendizaje como un proceso que nos aporta cosas positivas. En esta forma de ver el aprendizaje, los errores son sólo un paso que nos acerca a conseguirlo. Aquí el único fracaso es no intentar hacer las cosas, siendo una de las claves de nuestro empoderamiento aprender a aprender de nuevo, dejando la creencia transmitida de tener que ser perfectas y hacerlo todo perfecto: el físico, la comida, las tareas del hogar, la crianza de la descendencia, los estudios, el trabajo... en definitiva, todo.

\section{Resultados}

En una primera aproximación, estos talleres de coaching lo que aportan es la importancia de vivirlo como un proceso, concretamente, un proceso de aprendizaje ya que sólo los cambios que se mantienen en el tiempo son los que perduran. Unido a la toma de consciencia de cómo actuamos ante las diferentes situaciones. Como, por ejemplo, el dejar de actuar desde el papel de víctima y hacerlo desde el de protagonista o comportamientos más concretos como el conseguir ser puntual, decir no, dedicar tiempo a sus cosas, hacerlas sin sentimiento de culpabilidad y priorizarlas. Es cierto que durante el taller se han dado recaídas conductuales ante determinadas situaciones donde han vuelto comportamientos y actitudes aprendidas en el pasado. Estas se han dado, especialmente, a la hora de no ser capaz "decir que no" ante peticiones de familiares, dejando de hacer las cosas que eran importantes para ellas. Aun así, ya han incorporado esas 
nuevas herramientas y habilidades que les permitirán llegar hacia donde quieren ir, siendo esa meta la que guiará su camino.

Hay que destacar los resultados obtenidos de la comparación de las medias halladas de las respuestas obtenidas en el cuestionario inicial y en las obtenidas en la evaluación final a los ítems:

- ¿Cómo de segura te consideras?

- ¿Cómo te sientes de empoderada?

\begin{tabular}{l}
\hline Tabla 1. Comparación entre las respuestas del cuestionario inicial y la evaluación final \\
\begin{tabular}{|c|c|}
\hline Cuestionario inicial & Evaluación final \\
\hline ¿Cómo de segura te consideras? & 4,1 \\
\hline 2,37 & \\
\hline ¿Cómo te sientes de empoderada? & 4,3 \\
\hline 2,43 & \\
\hline
\end{tabular}
\end{tabular}

Fuente: elaboración propia.

Los datos nos muestran cómo tanto en relación a la seguridad como al empoderamiento las mujeres mostraban una puntuación mucho menor antes de los talleres que una vez finalizados. Además, esto se dio en el $100 \%$ de la muestra encuestada, por lo que podemos afirmar que tras la realización de los talleres las mujeres encuestadas se consideraban más seguras y se sentían más empoderadas que al inicio del taller.

\begin{tabular}{|c|c|}
\hline Cuestionario inicial & Evaluación final \\
\hline \multicolumn{2}{|l|}{ ESFERA 1. ¿Cómo de segura te consideras? } \\
\hline 2,4 & 4,1 \\
\hline \multicolumn{2}{|c|}{ ESFERA 2. Creo que es importante que las mujeres tengan ingresos económicos propios } \\
\hline 4,5 & 4,9 \\
\hline \multicolumn{2}{|l|}{ ESFERA 3. Una líder debe ser activa } \\
\hline 4,2 & 4,9 \\
\hline \multicolumn{2}{|c|}{ ESFERA 4. Mi vida actualmente la decido únicamente yo } \\
\hline 2,8 & 4,6 \\
\hline \multicolumn{2}{|c|}{ ESFERA 5. Mi familia ve muy bien que yo participe socialmente aunque esté menos tiempo en casa } \\
\hline 4,1 & 4,8 \\
\hline \multicolumn{2}{|c|}{ ESFERA 6. La familia debe educar a las mujeres para que tengan puestos de poder y liderazgo } \\
\hline 3,8 & 4,9 \\
\hline
\end{tabular}

Fuente: elaboración propia. 
Para presentar los resultados de empoderamiento se ha decidido hacerlo de manera desagregada por las diferentes esferas en las que Schuler considera que deben darse manifestaciones para llevar a cabo un proceso de empoderamiento, centrándonos tanto en el registro observacional realizado, en este sentido mostrando aspectos más cualitativos, como en datos cuantitativos extraídos de los cuestionarios iniciales y finales referentes a diferentes ítems que se corresponden a las diferentes esferas que se muestra a continuación:

\section{Sentido de seguridad y visión de futuro}

A nivel observacional podemos describir que las mujeres llegaban con una visión estática sobre su situación actual y su futuro. En su mayoría con una gran inseguridad. Eran mujeres que ni siquiera se atrevían a participar y que realizaron amistades dentro del grupo. En una sesión específica se trabajó la visualización de futuro, en la que todas se veían alcanzado diferentes metas en el plazo de uno o dos años. Entre las visualizaciones estaban las relacionadas con la consecución de un trabajo, la realización de un trabajo, las enfocadas a una mejora de la salud, a una mejora de las relaciones con su pareja u otros familiares, a aprender informática, pintura o bailar sevillanas, entre otras. La sesión en la que se trabajó la visualización fue la número 4 (Ver Cuadro 1), a mitad de curso, donde ya se observaba una mayor seguridad en sí mismas que les motivaba para, al menos, pensar en aquellas cosas que deseaban hacer pero sus miedos e inseguridades les impedían. Si nos fijamos en el ítem sobre la seguridad en sí mismas (Tabla 2) observamos cómo la seguridad era mayor al finalizar el taller que en su inicio.

\section{Capacidad de ganarse la vida}

Este puede ser el aspecto donde encontramos mayor hándicap en algunas mujeres para desarrollar plenamente su proceso de empoderamiento aunque sí se ha realizado en otras esferas. Y es que, a pesar de que puntúa muy alto, tanto al inicio como al finalizar el taller, el ítem "creo que es importante que las mujeres tengan ingresos económicos propios", un $70 \%$ se encontraban desempleadas y dependientes del salario de su pareja, o ascendientes. Otro $20 \%$ de ellas, al tener una pensión por incapacidad laboral o jubilación, en su mayoría ejercían de amas de casa, por lo que las sitúan en el ámbito de lo doméstico frente al ámbito de lo público. Hemos podido comprobar que tras el taller han valorado tanto el trabajo de sus compañeras como el suyo propio de ama de casa, dejando atrás la culpabilidad que muchas arrastraban a la hora de gastar dinero o realizar actividades. Tenemos mujeres que han iniciado un proceso de búsqueda de empleo, incluso otras que han conseguido un empleo, iniciándose algunas iniciativas desde la propia asociación, al emprenderse en ofrecer sesiones de flamenco, venta de artículos, peluquería a domicilio...

\section{Capacidad de actuar eficazmente en la esfera pública}

En este sentido, trabajamos la sesión sobre la comunicación y el hablar en público. A pesar de que en la primera sesión observamos algunas mujeres muy poco participativas, que expresaban tartamudez y cara enrojecida al hablar, cuando se desarrolló esta sesión ya mostraban más seguridad en sí mismas y confianza en el grupo. Destacar el caso de una usuaria que casi no le salía la voz del cuerpo en la primera sesión, incluso se bloqueó en una de las dinámicas que había que expresarse escribiendo y después leerlo. Como después nos trasladó, había aprendido a leer y a escribir de mayor y se sentía muy insegura. Esto nos sirvió 
para adaptar algunas dinámicas e intentar que en su mayoría trabajaran en parejas. Este caso fue uno de los más llamativos porque no se relacionaba con nadie al comenzar el taller, y actualmente no hay un jueves que se pierda los "juernes lunáticos"3. En relación al ítem "una líder debe ser activa”, en el cuestionario inicial las mujeres compartían con un 4,2 esta afirmación, al finalizar los talleres la valoraban en 4,9 (Ver Tabla 2). Esto se observa en la participación en las actividades desarrolladas desde la asociación, que van desde talleres a las asambleas de la asociación, así como invitaciones a actos de otras instituciones como la Diputación, el Ayuntamiento u otras entidades (no podemos cuantificar el aumento de participación al no contemplar un registro ni anterior ni posterior, aunque sí afirmar que el aumento ha sido considerable, aumentando durante este período en 90 el número de socias de la Asociación LUNA).

\section{Mayor poder de tomar decisiones en el hogar}

Es cierto que nos encontramos en este ámbito aspectos en los que las mujeres ejercen la toma de decisiones sobre la crianza de las hijas y los hijos, en algunos aspectos de la economía, en la organización del hogar... Pero a la hora de tener la última palabra hacían referencia a la figura masculina del hogar. Aquí nos llegamos a encontrar el caso de una mujer que mostraba manifestaciones de empoderamiento en el resto de las esferas y en una de las sesiones tiene un quiebre. Ella se había formado ya de más mayor, actualmente se encontraba trabajando, había hecho amistades tanto en la carrera como en el trabajo y la habían invitado a una barbacoa. Su marido se había enfadado y no quería que fuera. Ella no sabía qué hacer y se sentía culpable. Finalmente, decidió ir a pesar del enfado de su marido. Situaciones como éstas o juicios en este sentido fueron muy comunes en las sesiones, por lo que la cuestión de género fue trabajada de manera transversal a lo largo de todo el taller, mediante dinámicas de reflexión y técnicas como la visualización.

En relación con los datos cuantitativos relacionados con el cuestionario, éstos son significativos entre el cuestionario inicial y el final (ver Tabla 2), con una mayor puntuación a la hora de decidir sobre su vida al finalizar el taller que al inicio de éste. Habría que destacar en este sentido los datos referentes al ítem "Es mejor que sea el hombre el que tome las decisiones importantes", ya que al inicio del taller las mujeres manifestaban estar de acuerdo con un 4,6b frente al 1,2 al finalizar el taller, mostrando que estaban totalmente en desacuerdo.

5. Participación en grupos no familiares y uso de grupos de solidaridad como recursos de información y apoyo

En este sentido, pudimos observar la participación en nuestra propia asociación, que ha conllevado un aumento de actividades y la creación de los "juernes lunáticos” ya comentada, donde además de crear un espacio para conversar, visitamos exposiciones culturales, vamos al cine... También se creó un grupo de WhatsApp donde las mujeres se relacionan y expresan cómo se encuentran, además de quedar entre ellas por su propia iniciativa. También hay mujeres que tenían fibromialgia y se han informado y asociado en la asociación específica sobre fibromialgia. Hemos tenido casos que necesitaban recursos específicos, lo han expuesto y se ha buscado el recurso apropiado, entre ellos, el de la Federación de Personas con Discapa-

3. Actividad que surgió en el desarrollo de los talleres como un espacio donde conversar, compartir y crear nuevas relaciones en un ambiente distendido (una cafetería) mientras compartíamos un café, así como actividades de tipo lúdicas: ir al cine, teatro, conciertos, exposiciones culturales... 
cidad en Huelva (Cocemfe), bien para federarse, para solicitar una revisión del grado de discapacidad o por motivos jurídicos. En este sentido, en el ítem que hace referencia a esta esfera, "mi familia ve muy bien que yo participe socialmente, aunque esté menos tiempo en casa" (ver Tabla 2), aunque la puntuación era alta en el inicio y, en este sentido, había mujeres que manifestaban haber acudido motivadas por las hijas, su puntuación es aún mayor al finalizar el taller. Podría tener que ver según manifestaban que se sentían más contentas y de mejor humor, aunque esto no podemos demostrarlo.

\section{Movilidad y visibilidad en la comunidad}

Durante el desarrollo de los talleres ha habido un aumento de la participación en foros y espacios en los ámbitos de la discapacidad y de las mujeres, participando en el Encuentro de Asociaciones federadas de Cocemfe (KM0), asistiendo más de 30 usuarias a los Premios Meridiana en Sevilla -donde se desplazaron en autobús proporcionado por el Instituto de la Mujer y visitaron la ciudad-. También en los Premios Marismas de Huelva donde asistieron alrededor de 15 mujeres, en el Seminario de Mujeres Asociadas 2017 donde intervino Marcela Lagarde, acudiendo cerca de diez mujeres, o en diferentes foros como el I Foro Social de Mujeres con Discapacidad en Sevilla, donde pernoctaron y se relacionaron con mujeres de otras ciudades de España (aquí sólo participaron cuatro mujeres, ya que conllevaba un coste económico por parte de las usuarias). Además, dos de las usuarias han participado en una investigación sobre los recortes en sanidad realizada por Amnistía Internacional. Las usuarias han participado también de manera activa en las manifestaciones por la Igualdad de la Mujer o contra la Violencia de Género donde acudieron alrededor de 25 mujeres.

\section{Conclusiones}

Como recoge León et al. (1997), tanto empoderamiento como empoderar son términos que recogen acción, al igual que el coaching, que requiere de la acción no sólo en la reflexión de qué y hacia dónde quiero ir, además necesita del cómo. Y es en la acción donde ambos otorgan el poder recuperado a la persona, en nuestro caso a las mujeres con discapacidad, para poder hacer lo que quieran en todos los ámbitos, tanto públicos como privados, recuperando aquellas esferas, profesiones, decisiones, derechos y oportunidades que históricamente nos han sido negadas. De esta manera, coaching y empoderamiento van de la mano, desterrando falsos estereotipos y creencias existentes hacia las mujeres y facilitando un espacio donde poder crear cada una su propia imagen: imágenes nuevas, diferentes, libres de juicios y validadas en la acción.

Según lo expuesto, entonces ¿podemos afirmar que las mujeres con discapacidad de la asociación LUNA han alcanzado el empoderamiento a través del coaching?

Podemos afirmar que las mujeres que han pasado por los talleres de coaching manifiestan sentirse más empoderadas que cuando empezaron, así como considerarse más seguras de sí mismas. Esto toma un peso llamativo acompañado de las manifestaciones observadas citadas anteriormente. Muchas mujeres lo han tomado como un camino que no ha hecho más que empezar, ya que han conseguido el control de 
sus vidas, pasando a ser protagonistas y dejando el papel de víctimas. Tanto mediante la creatividad como con el descubrimiento y entrenamiento de nuevas herramientas, han experimentado y logrado hacer cosas acordes y deseables para cada una de ellas. Han comenzado a definir sus propias agendas, trabajando la planificación y participando en actividades formativas, culturales, sociales y participativas.

Después del taller de coaching, las mujeres han seguido formando parte activa de nuestra asociación, participando en los talleres y actividades organizadas teniendo en cuenta sus intereses (recogidos en las evaluaciones), así como en manifestaciones relacionadas con el empoderamiento o igualdad de la mujer. Los talleres y actividades en los que han participado son, entre otros, sevillanas, musicoterapia, sexualidad, meditación... manteniéndose también la actividad de los "juernes lunáticos”. Además, se han llevado a cabo cinco procesos de coaching individual con mujeres que participaron en el taller, así como alrededor de 20 entrevistas informales sobre cómo se encontraban.

Tras estos resultados, a finales de febrero iniciamos los talleres de "Coaching para el Empleo" que finalizarán a finales de junio de 2018. En esta ocasión (algunas de las mujeres participaron en el primer Taller de "Coaching en clave de Género" aquí presentado) se prevé y se han estructurado evaluaciones trimestrales posteriores a su finalización para evaluar los logros obtenidos: entrevistas realizadas, formaciones, contrataciones...

Y es que, sin miedo a equivocarse ni al qué dirán o pensarán de ellas, estas mujeres han iniciado un camino de crecimiento personal hacia la libertad de ser las mujeres que son y quieren ser. En palabras de Virginia Wolf "no hay barrera, cerradura ni cerrojo que puedas imponer a la libertad de mi mente".

Son mujeres con discapacidad empoderadas que se permiten soñar y son capaces de hacer sus sueños realidad.

Transformando unos versos que nos regaló el hijo de una compañera de viaje, finaliza este senderismo a la espera de un nuevo destino:

\footnotetext{
Me he vuelto a alzar, e impulso he cogido

Sin dejar atrás lo que he vivido

Mi corazón no teme al miedo

Que ya fue su prisionero

Y mi pasión le ha vencido.
} 


\section{Referencias bibliográficas}

Bielecki, J. y Swender, L. S. (2004): "The assessment of social functioning in individuals with mental retardation". Behaviour Modification, 28: 694-708.

Charlier, S y Caubergs, L. (2007): El proceso de empoderamiento de las mujeres. Guía metodológica. Bruselas: Comisión de Mujeres y Desarrollo.

Cook, R. J. (1977): Los derechos de las mujeres, perspectivas nacionales e internacionales. Bogotá: Profamilia.

Guil, M. (2006): Escala mixta Likert- Thurstone. Revista Andaluza de Ciencias Sociales, 5: 81-95.

Hernández, J y García, R. (2008): Instrumento para medir el empoderamiento de la mujer. Villahermosa, Tabasco: Universidad Juárez Autónoma de Tabasco.

Jiménez, A. (2017): Personas con discapacidad y discriminación múltiple en España: situación y propuestas. Madrid: Observatorio Estatal de la Discapacidad.

León, M. (comp.) (1997): Poder y empoderamiento de las Mujeres. Bogotá: Tercer Mundo Editores y Fondo de Documentación Mujer y Género de la Universidad Nacional de Colombia.

Morales, P. (2006): Medición de actitudes en psicología y educación: construcción de escalas y problemas metodológicos. Madrid: Universidad Pontificia Comillas.

Ortega, R. et al. (2000): “Autoestima: un nuevo concepto y su medida”. Teoría de la Educación. Revista Interuniversitaria, 12: 45-66.

Pittini, K. (2015): Coaching: una herramienta para empoderar y transformar (en línea). <https://internationalcoachingcommunity.com/es/coaching-una-herramienta-para-empoderar-y-transformar/>, acceso 14 de mayo de 2018.

Ravier, L. (2005): Arte y ciencia del Coaching. Su historia filosofía y esencia. Buenos Aires: Unión Editorial.

Sans, M. (2012): “¿Qué es el coaching? Sus orígenes, definición, distintas metodologías y principios básicos de actuación de un coach". 3c Empresa: investigación y pensamiento crítico, 1 (3).

Schuler, M. (1997): Los derechos de las mujeres son derechos humanos: la agenda internacional del empoderamiento, en De León, M. (comp.) (1997): Poder y empoderamiento de las Mujeres. Bogotá: Tercer Mundo Editores y Fondo de Documentación Mujer y Género de la Universidad Nacional de Colombia.

Whitmore,J. (2003): Coaching. El metodo para mejorar el rendimiento de las personas. Barcelona: Paidós.

Wolk, L. (2003): Coaching. El arte de soplar las brasas. Buenos Aires: Gran Aldea Editores. 